Gut, 1967, 8, 565

\title{
Cystic arterial patterns in diseased human gall bladders
}

\author{
K. C. D. GORDON \\ From the Surgical Unit, The London Hospital
}

EDITORIAL COMMENT Attention is drawn to arterial vascular changes associated with cholecystitis. There may be patchy distortion and reduction of blood supply and these changes may be present at an early stage in the natural history of the disease.

Over the last 20 years various authors have suggested that local vascular factors may play some part in the aetiology of certain diseases of the gall bladder (Eliason and Stephens, 1944; Goldman, Morgan, and Kay, 1948; Hallendorf, Dockerty, and Waugh, 1948; Strohl, Diffenbaugh, Baker, and Cheema, 1962; Thomas and Womack, 1952). This paper describes an attempt to establish whether the gross arterial architecture of the diseased gall bladder differs from that of the normal organ, and whether any such differences can be correlated with the nature of the local disease.

Using a technique developed in a comparative anatomical study of man and 34 other species (Gordon, 1967), the arterial patterns found in 48 diseased gall bladders were compared with those found in 75 normal gall bladders. This technique involved injecting the gall bladder arteries with Micropaque, filling the lumen of the organ with a translucent resin, and rendering the wall transparent with a clearing agent. The injected arteries then showed up clearly against the translucent gall bladder.

\section{FINDINGS}

NORMAL GALL BLADDERS Seventy-five specimens, obtained at necropsy, were studied. The pattern of distribution of the arteries in the wall of the normal human gall bladder (Fig. 1) has already been described in detail (Gordon, 1967). Briefly, it was found that the human cystic artery is not in contact with any part of the cystic duct, in contrast to the findings in 34 other species. After a short course on the gall bladder it divides into two longitudinal branches, which course to the fundus of the viscus and there each of these divides into two branches, which anastomose to form a diamond-shaped pattern. Lateral branches from each of the main longitudinal vessels pass round the body of the organ to form encircling arterial anastomoses. Between the vessels described above fine branches form a delicate reticulate anastomosis. This arrangement of arteries was constant in the 75 specimens.

DISEASED GALL BLADDERS Forty-eight operation specimens were studied. Of these four were muco coeles containing calculi, 17 were externally normal but contained calculi, and 27 showed chronic cholecystitis.

Mucocoeles of the four mucocoeles injected, three showed a normal pattern in all respects. In the other, which showed some external evidence of cholecystitis in the form of thickening of the gall bladder wall, all the arteries filled well, but many of the smaller vessels were tortuous.

Externally normal gall bladders containing calculi Seventeen operation specimens containing calculi were externally normal, that is, the gall bladder wall was the normal slate-blue colour, it was not thickened, and there was little or no fat between the muscular layer and the outer serous coat. The arterial patterns shown by injection were normal or showed minor tortuosity of the small vessels and occasional areas of patchy filling of the fine reticulate anastomosis.

CHRONIC CHOLECYSTITIS Twenty-seven operation specimens showed varying degrees of macroscopic evidence of chronic cholecystitis, that is, grey colour, thickening of the wall, and excess of subperitoneal fat. These specimens showed the following abnormalities in the arterial patterns (Fig. 2): no filling of one or more named vessels; no filling of small vessels, and frequently large areas of the gall bladder had no injected arteries; many small vessels filled for very short distances so that the fine reticulate anastomosis was not apparent; in some speci- 
FIG. 1. Injected and cleared normal gall bladder $\left(\times 1 \frac{1}{2}\right)$. The arteries have been injected with Micropaque and the wall of the organ has been cleared, revealing the normal human arterial pattern.

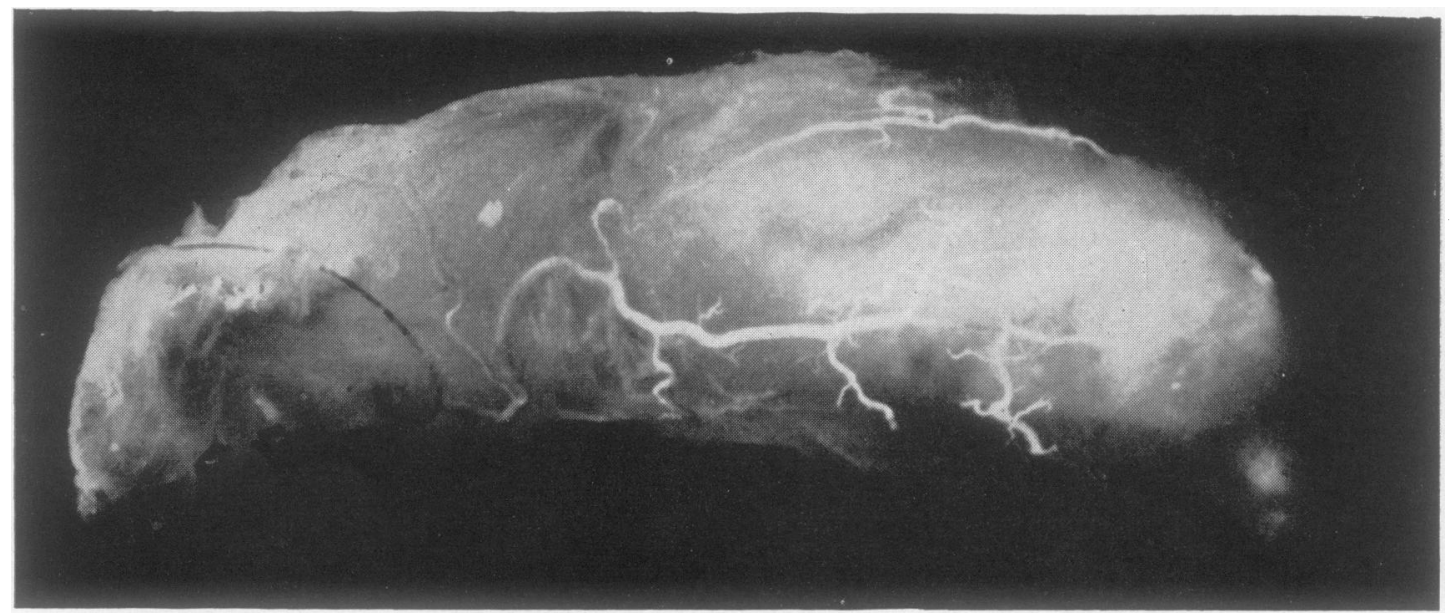

FIG. 2. Injected and cleared gall bladder $\left(\times 1 \frac{1}{2}\right)$. The organ is filled with a mass of white calculi and showed all the appearances of advanced chronic cholecystitis. Gross derangement of the arterial pattern is present (see text).

mens the outline of the major arteries was irregular and tortuous.

Vascular abnormalities were present in these diseased gall bladders whether or not they contained calculi. They did not appear to bear any relation to the number of calculi, where these were present, or to their size.

CORRELATION OF SEVEN FACTORS IN HUMAN POSTMORTEM FINDINGS WITH THE ARTERIAL FACTORS It seemed possible that the pattern of the arteries of the gall bladder might be altered by factors other than local gall bladder disease. The 75 normal gall bladders were, therefore, divided into groups on the basis of the post-mortem data. It was found that the arterial pattern was not altered by age, systolic or diastolic hypertension, coronary thrombosis, or 32 other diseases which had caused death. No sex difference was apparent.

Sixteen specimens were taken from subjects with severe atheroma, that is, the aorta contained massive ulcerated, calcified, and confluent plaques. Six of these showed normal arterial patterns in all respects. The remaining 10 specimens showed good filling of the cystic artery and its main longitudinal and fundal branches. The small unnamed arteries, which form 


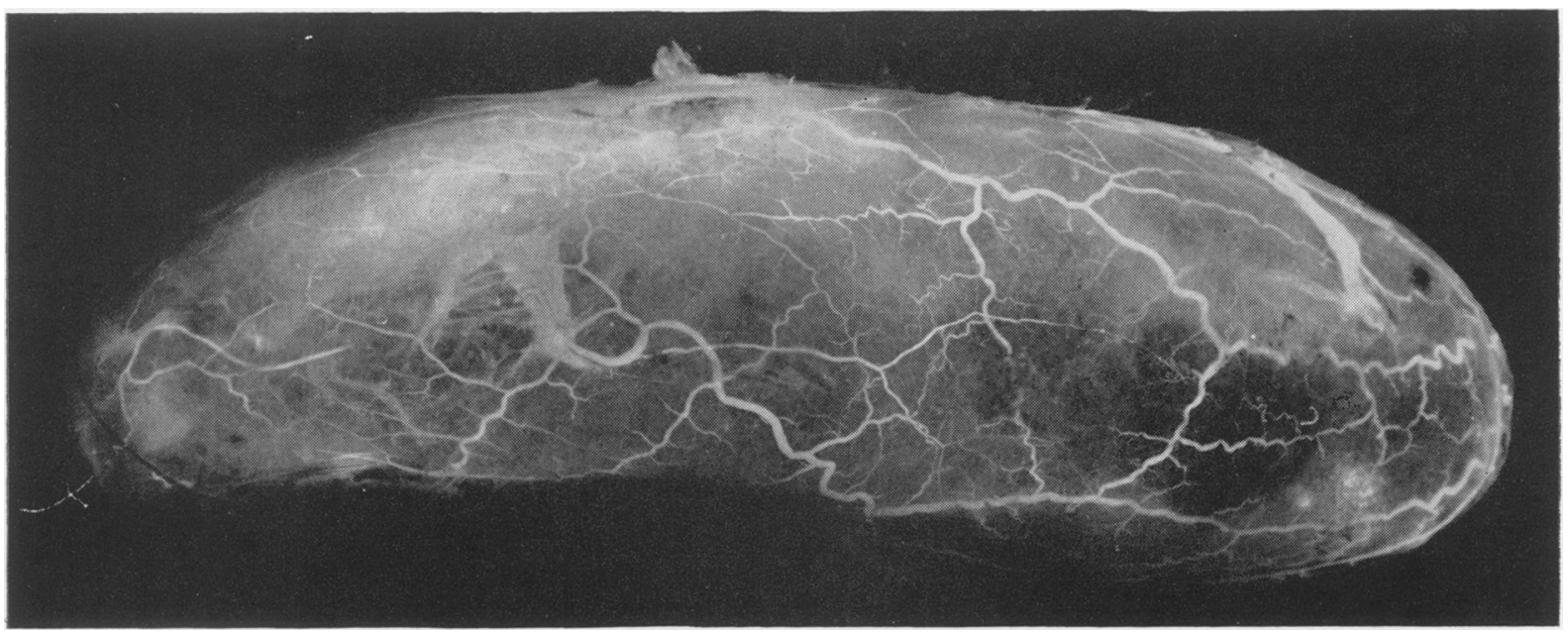

FIG. 3. Injected and cleared gall bladder $\left(\times 1 \frac{1}{2}\right)$. The specimen contains calculi and showed slight evidence of chronic cholecystitis. The arterial pattern is abnormal (see text).

the fine reticulate anastomosis, filled patchily, so that small areas of the gall bladders showed no injected vessels.

\section{DISCUSSION}

The arterial patterns exhibited by diseased gall bladders do not seem previously to have received attention. There have been frequent macroscopic studies of the arteries within different organs, sometimes to show vessels which may be of significance in operative surgery or to establish the source of arterial supply, and less frequently to demonstrate special features such as arteriovenous shunts (Barclay, 1951). To date most of these studies have been confined to disease-free organs.

It was found early in this study that existing injection techniques were more suitable for solid organs. The technique developed in the early stages of this work and used throughout has advantages for the study of the vasculature of hollow organs. Filling the lumen of the organ with a liquid resin which polymerises to form a permanent, solid, and transparent mass prevents the organ collapsing and thereby obscuring the vessel pattern. Subsequent clearing of the wall of the viscus demonstrates the injected vessels clearly both for naked-eye study and photography. Structures in the lumen of the organ, such as gall stones, are easily seen embedded in the resin.

The method has certain disadvantages. Only intact specimens can be injected completely, and hence no histological information can be obtained about the actual organs injected. There is no microscopic proof that the gall bladders showing arterial changes were in fact diseased. The external appearances of gall bladder disease, however, have been clearly defined (Boyd, 1955). If a gall bladder is grey or white and its wall is grossly thickened and opaque, with an abnormal amount of subserosal fat, it may be taken to be diseased. These features are generally accepted as reliable evidence of gall bladder disease, and have been used as the criteria of disease in the specimens described in this study.

Three of the four mucocoeles, all of which contained calculi, had normal patterns.

Specimens containing calculi but without external evidence of cholecystitis showed normal patterns or some tortuosity and minor filling defects of the fine vessels forming the reticulate anastomosis between the main arteries.

Operation specimens which showed external evidence of cholecystitis revealed gross arterial changes. It was notable that these changes were wellmarked in specimens in which the features of chronic cholecystitis were of slight or moderate degree (Fig. 3). Many of these gall bladders showed large areas in which no vessels had been injected. Frequently the outline of the main vessels was irregular and tortuous.

The surgically removed gall bladders described here fell into two groups, when considered from the viewpoint of their arterial patterns. One group contained calculi, but did not show external evidence of cholecystitis, and in these the distribution of the arteries was virtually normal. In the other group, some of which did not contain calculi, arterial disturbances were shown which were proportional in severity to the magnitude of the macroscopic evidence of cholecystitis, and were present even when 
this evidence was minimal. These findings suggest that in human gall bladders, minimally affected by cholecystitis, the early arterial changes appear in the smallest vessels, the cystic artery itself or its major branches only being involved as the disease becomes more advanced. Since no microscopic survey was carried out (v. supra) this study does not decide whether these changes arise from the subintimal oedema and intimal proliferation observed in 23 of 100 cases of gangrenous cholecystitis described by Hallendorf et al. (1948).

A study of 75 normal human gall bladders removed at necropsy showed that similar changes are not associated with ageing, hypertension, coronary thrombosis, or 32 other diseases causing death. Ten of 16 specimens from patients with severe atheroma in the aorta showed some minute arterial branches failing to fill, but no tortuosity or other changes similar to those shown in the group of gall bladders with chronic cholecystitis.

The question of whether the arterial abnormalities in diseased gall bladders are a factor in the aetiology of cholecystitis, or whether they are secondary to it and possibly increased with each subsequent attack, is not decided by this study. Some specimens presented here, however, showed well-marked arterial changes with little external evidence of disease. If the second hypothesis, that the changes observed originate during or following the initial attack of cholecystitis, is correct, the question of their effect upon the incidence and severity of subsequent attacks is raised.

That these changes were not due to mechanical obstruction of the cystic duct nor to the presence of calculi was suggested by the findings in the mucocoeles and in the specimens containing calculi when the gall bladder appeared normal. One mucocoele which showed minimal external evidence of cholecystitis revealed only minor disturbances in its arterial pattern, whilst the other three had normal patterns. In these specimens prolonged obstruction of the cystic duct had produced no significant changes in the arterial pattern. It would appear to be unlikely, therefore, that either simple mechanical obstruction of the cystic duct or the presence of gall stones could account for the abnormalities in the arterial pattern observed in gall bladders with chronic cholecystitis. Furthermore, the observation that well-marked arterial changes are present in gall bladders showing only slight evidence of disease raises the possibility that these abnormalities are the precursor of the fibrosis of the organ which is the outstanding characteristic of chronic cholecystitis.

\section{SUMMARY AND CONCLUSION}

The arterial pattern has been studied in $\mathbf{4 8}$ diseased human gall bladders removed at operation, and in 75 normal human gall bladders from cadavers.

When chronic cholecystitis was advanced the vascularity of the gall bladder was patchy and greatly reduced and gross distortion of its arterial pattern was present. When the gall bladder wall showed less severe external evidence of cholecystitis, extensive arterial changes of similar type were revealed. Whether such disturbances of the arterial pattern are the cause or the sequel of the initial attacks of cholecystitis is not decided by this study, but they were found to be already established at an early stage in the natural history of the disease.

Normal patterns in mucocoele specimens suggested that the arterial changes seen in gall bladders with chronic cholecystitis were not due to simple mechanical obstruction of the cystic duct, nor to the presence of calculi.

The arterial changes demonstrated were not associated with ageing, coronary thrombosis, hypertension, atheroma, or 32 other diseases causing death.

It is concluded that the characteristic changes of chronic cholecystitis are accompanied by progressive abnormalities of the gall bladder arteries, which are present at an early stage in the natural history of the disease, and may be concerned in its aetiology.

I am pleased to record my gratitude to the surgeons and pathologists at The London Hospital for the specimens, and to the Boards of Governors of The London Hospital and The London Hospital Medical College for meeting most of the expenses of this study.

\section{REFERENCES}

Barclay, A. E. (1951). Micro-Arteriography, p. 66, Blackwell. Oxford. Boyd, W. (1955). Pathology for the Surgeon, 7th ed., p. 246 Saunders. Philadelphia and London.

Eliason, E. L., and Stephens, L. W. (1944). Acute cholecystitis. Surg. Gynec. Obstet., 78, 98-103.

Goldman, L., Morgan, J. A., and Kay, J. (1948). Acute cholecystitis. Gastroenterology, 11, 318-325.

Gordon, K. C. D. (1967). A comparative anatomical study of the distribution of the cystic artery in man and other species. J. Anat. (Lond.), 101, 351-359.

Hallendorf, L. C., Dockerty, M. B., and Waugh, J. M. (1948). Gangrenous cholecystitis: a clinical and pathological study of 100 cases. Surg. Clin. N. Amer., 28, 979-998.

Strohl, E. L., Diffenbaugh, W. G., Baker, J. H., and Cheema, M. H. (1962). Gangrene and perforation of the gallbladder. Int. Abstr. Surg., 114, 1-7.

Thomas, C. G., Jr., and Womack, N. A. (1952). Acute cholecystitis, its pathogenesis and repair. Arch. Surg., 64, 590-600. 